\title{
A Comparison of Brand and Biosimilar Granulocyte-Colony Stimulating Factors for Prophylaxis of Chemotherapy-Induced Febrile Neutropenia
}

\author{
Andrea G. Douglas, PharmD; Phil Schwab, PhD; Daniel Lane, PharmD, PhD; \\ Kenneth Kennedy, PharmD, MS, BCOP; S. Lane Slabaugh, PharmD, MBA; and Andy Bowe, MPH
}

\begin{abstract}
BACKGROUND: Filgrastim-sndz, a granulocyte-colony stimulating factor (G-CSF), was introduced as a biosimilar to filgrastim in 2015 , but realworld comparative effectiveness for filgrastim versus filgrastim-sndz has not been reported to date.

OBJECTIVES: To (a) compare the incidence of febrile neutropenia for patients taking filgrastim versus those taking filgrastim-sndz and (b) compare the incidence of a potential serious adverse event for filgrastim versus filgrastim-sndz.
\end{abstract}

METHODS: This retrospective cohort study identified patients receiving a G-CSF following chemotherapy, using administrative claims from the Humana Research Database. Patients enrolled in a Medicare Advantage Prescription Drug plan with a claim for a G-CSF from October 1, 2015, through September 30, 2016, were identified. G-CSF use had to occur within 6 days of exposure to chemotherapy and without any subsequent chemotherapy within 14 days after G-CSF use. Febrile neutropenia requiring hospitalization was defined as hospitalization within 14 days after G-CSF use with (a) diagnosis of infection and/or neutropenia (broad definition) or (b) infection and neutropenia diagnoses (narrow definition). Serious adverse drug events (spleen rupture, acute respiratory syndrome, serious allergic reactions, capillary leak syndrome, thrombocytopenia, leukocytosis, cutaneous vasculitis, or bones and muscle ache) were also identified within 14 days after G-CSF use. An incidence difference of $<1 \%$ with $90 \% \mathrm{Cl}$ crossing zero qualified as support for noninferiority. Two-tailed chi-square tests were also used to investigate differences.

RESULTS: A total of 88 filgrastim and 101 filgrastim-sndz patients were identified. Filgrastim and filgrastim-sndz met the criteria for noninferiority based on an incidence difference of $-0.6 \%(90 \% \mathrm{Cl}=-5.1 \%-4.0 \%$;

$P=0.84)$ for the broad definition of febrile neutropenia and a difference of $-0.8 \%(90 \% \mathrm{Cl}=-3.8 \%-2.1 \% ; P=0.64)$ for the narrow definition. For the analysis of serious adverse events, an incidence difference of $-2.5 \%(90 \%$ $\mathrm{Cl}=-7.5 \%-2.5 \% ; P=0.42$ ) for filgrastim compared with filgrastim-sndz was not sufficient to establish noninferiority.

CONCLUSIONS: This study is one of the first analyses of real-world evidence regarding the noninferiority of filgrastim and filgrastim-sndz. The study results support noninferiority of filgrastim and filgrastim-sndz for prevention of febrile neutropenia requiring hospitalization. While noninferiority for serious adverse events was not supported, there was also no statistically significant difference between filgrastim and filgrastim-sndz. The study's small sample size could have limited the analysis of the relatively rare outcomes of febrile neutropenia requiring hospitalization and serious adverse events. A study including a larger numbers of patients taking filgrastim or filgrastim-sndz could provide additional insights.

J Manag Care Spec Pharm. 2017;23(12):1221-26

Copyright $\odot 2017$, Academy of Managed Care Pharmacy. All rights reserved.

\section{What is already known about this subject}

In trial studies for granulocyte-colony stimulating factors such as filgrastim, neutropenia, which can lead to infection and require hospitalization, was assessed based on absolute neutrophil count. Noninferiority of filgrastim and filgrastim-sndz for prevention of neutropenia, as measured by absolute neutrophil count, has been established via evidence from a randomized controlled trial.

\section{What this study adds}

Using real-world administrative claims data, this study assessed noninferiority for the biosimilar filgrastim-sndz relative to its reference product filgrastim in terms of effectiveness.

Filgrastim and filgrastim-sndz were noninferior based on the outcome of neutropenia that requires hospitalization.

Noninferiority of filgrastim and filgrastim-sndz based on serious adverse events was not supported by this study, but a larger sample may be needed to evaluate serious adverse events since they are relatively rare.

I n March 2010, a provision in the Patient Protection and Affordable Care Act created an abbreviated approval pathway for biosimilars that supported industry innovation and consumer interests. ${ }^{1}$ This provision, the Biologic Price Competition and Innovation Act (BPCIA), aimed to authorize the production of "highly similar" molecules to biological products approved by the U.S. Food and Drug Administration (FDA). ${ }^{1}$ In March 2015, filgrastim-sndz, a granulocyte-colony stimulating factor (G-CSF), was approved as the first marketed biosimilar in the United States. ${ }^{2}$ In oncology settings, G-CSF therapy is most commonly used to increase the production of granulocytes in patients undergoing myelosuppressive chemotherapy. For these patients, a significant reduction in circulating granulocytes increases the risk of febrile neutropenia and severe, life-threatening infections.

Filgrastim-sndz shares 5 FDA-approved indications with its reference product filgrastim (Table 1). ${ }^{3,4}$ Another agent in this class is tbo-filgrastim, ${ }^{5}$ which is not considered a biosimilar because its approval predated BPCIA, and it went through the Biologics License Application submission process. The fourth G-CSF option, pegfilgrastim, is filgrastim that has been modified 


\section{TABLE 1} FDA-Approved Indications for Filgrastim and Filgrastim-sndz

\begin{tabular}{l} 
Filgrastim and filgrastim-sndz are \\
leukocyte growth factors indicated to do the following: \\
- Decrease the incidence of infection, as manifested by febrile neutropenia, \\
in patients with nonmyeloid malignancies receiving myelosuppressive \\
anti-cancer drugs associated with a significant incidence of severe \\
neutropenia with fever 3,4 \\
- Reduce the time to neutrophil recovery and the duration of fever, following \\
induction or consolidation chemotherapy treatment of patients with acute \\
myeloid leukemia 3,4 \\
- Reduce the duration of neutropenia and neutropenia-related clinical \\
sequelae 3,4 \\
- Mobilize autologous hematopoietic progenitor cells into the peripheral \\
blood for collection by leukapheresis,4 \\
- Reduce the incidence and duration of sequelae of severe neutropenia \\
(e.g., fever, infections, oropharyngeal ulcers) in symptomatic patients with \\
congenital neutropenia, cyclic neutropenia, or idiopathic neutropenia \\
\hline Note: Filgrastim is additionally indicated to increase survival in patients acutely \\
exposed to myelosuppressive doses of radiation (hematopoietic syndrome of acute \\
radiation syndrome). ${ }^{4}$ \\
FDA=U.S. Food and Drug Administration.
\end{tabular}

by pegylation, which confers more prolonged bioavailability and is the most commonly used G-CSF in this class. ${ }^{6}$ Pegfilgrastim is also not considered a biosimilar to filgrastim. This study focused on filgrastim and its biosimilar filgrastim-sndz.

Although there are multiple products available within the G-CSF drug class, there are a few challenges associated with prescribing them. Unlike with generic and reference brand drugs, a biosimilar may not be interchangeable with its reference product without intervention from the prescriber, unless interchangeability for the product has been authorized by state regulations. In addition, because of the abbreviated pathway used to approve biosimilars, there is typically less robust clinical trial data available at the time of product approval. ${ }^{7}$ One or more well-designed studies establishing noninferiority to the reference product are usually sufficient for FDA approval without the requirement of multiple placebo-controlled trials that often precede the approval of an originator drug. A comparison of the efficacy and safety of filgrastim-sndz versus filgrastim for controlling chemotherapy-induced neutropenia found that both agents were similar based on the rate of grade 4 neutropenia, as assessed by examination of patients, in the first treatment cycle. ${ }^{8}$

While filgrastim-sndz and filgrastim have been shown to be highly similar with no clinically meaningful differences in reducing the incidence of febrile neutropenia in a randomized controlled trial setting where patient selection, conditions, and observations may be more ideal, comparative effectiveness for filgrastim versus filgrastim-sndz has not been studied to date using observations from real-world practice., $3,7,8$ Hence, the purpose of this study was to compare effectiveness of various
G-CSF products in reducing the risk of febrile neutropenia in a real-world setting, using retrospective observations from health care administrative claims data.

\section{Methods}

\section{Study Design}

This retrospective, longitudinal cohort study identified patients with a medical or pharmacy claim (plan or patient paid) for a G-CSF (filgrastim or filgrastim-sndz) from October 1, 2015, through September 30, 2016. G-CSF claims had to occur after exposure to chemotherapy and without a subsequent round of chemotherapy for at least 14 days to allow for observation of febrile neutropenia, if any, and serious adverse events, if any, over the 14-day period.

\section{Data Source}

Data for this study were from the Humana Research Database. Humana is a health and well-being company serving millions of people across the United States through a Medicare Advantage Prescription Drug (MAPD) plan, stand-alone Prescription Drug Plan (PDP), and commercial plan offerings. The database has national coverage with a high proportion of individuals from Texas, Florida, and Ohio and is one of the largest MAPD claims databases. For this study, medical and pharmacy claims for the MAPD and commercial populations were examined. Medical claims data included information regarding physician visits, outpatient visits, emergency department (ED) visits, and hospitalizations. Pharmacy claims data included detailed information on each individual's prescription fill. The full study period was from October 1, 2015, through September 30, 2016. The study protocol was reviewed and approved by Schulman and Associates Institutional Review Board.

\section{Sample Selection}

To be included in this study, patients had to have a claim for filgrastim or filgrastim-sndz within 6 days after a claim for a chemotherapy agent. The date of the first claim for filgrastim or filgrastim-sndz was defined as the index date. Patients had to be aged 18-89 years (19-89 if residing in Alabama or Nebraska where those under 19 are minors) and have at least 6 days of continuous plan enrollment before the index date to verify chemotherapy exposure and 14 days of continuous enrollment after the index date to observe study outcomes. Patients with a subsequent exposure of chemotherapy within 14 days were excluded from the study.

\section{Outcome Measures}

The proportion of patients with a febrile neutropenia outcome in which hospitalization was required and the proportion of patients with a potential serious adverse event after G-CSF use were observed during the 14 days after the index date. Febrile neutropenia requiring hospitalization was measured 


\section{FIGURE 1 Patient Flow Chart}
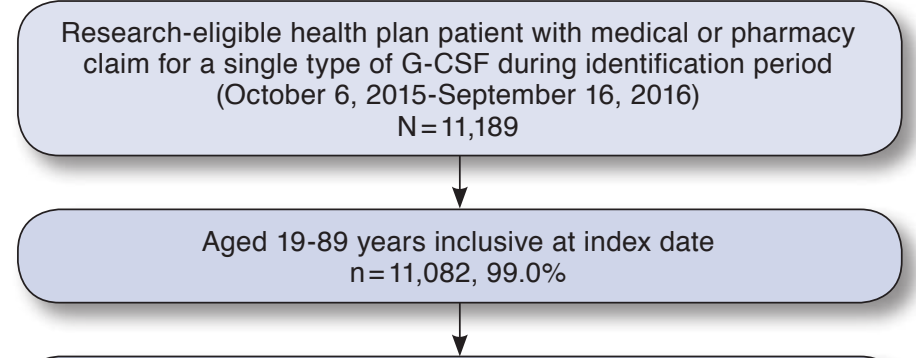

Continuous enrollment during baseline period ( 6 days pre-index enrollment) and follow-up period ( 14 days post-index enrollment) $n=10,844,96.9 \%$

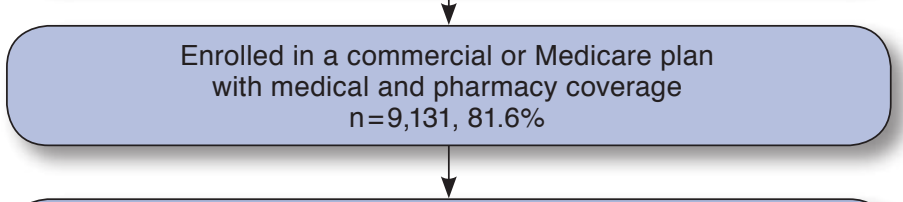

Exposure to chemotherapy during the baseline period $n=7,742,69.2 \%$

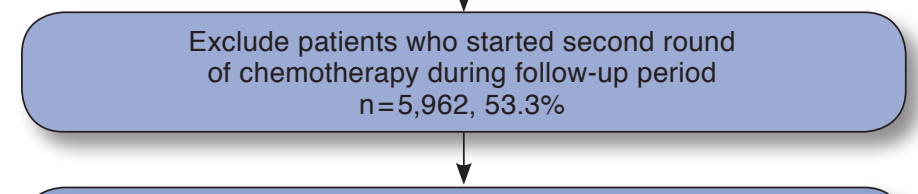

Exclude patients who used pegfilgrastim or tbo-filgrastim rather than filgrastim or filgrastim-sndz $n=189,1.7 \%$

G-CSF= granulocyte-colony stimulating factor

2 ways - one based on a broad definition and the other using a more conservative, narrow definition. ${ }^{9}$ The broad definition of febrile neutropenia was defined as hospitalization with a diagnosis of neutropenia (International Classification of Diseases, Tenth Revision, Clinical Modification [ICD-10-CM] code D70.x) or infection (ICD-10-CM codes A04, A08, A09, A39-A41, A48A49, B00-B09, B30-B34, B35-B49, B95-B97, B99, J00-J06, J09J18, J20-J22, K12, K57, K61, K81, K85, L00-L08, N10-N12, N15-N16, N39.0, R50, and R78.81). The narrow definition of febrile neutropenia required hospitalization with both neutropenia and infection diagnoses. ${ }^{9}$ For serious adverse events potentially related to G-CSF exposure, a composite measure was used that included claims for spleen rupture (ICD-10-CM code D73.81), acute respiratory syndrome (J80), serious allergic reactions (T88.6), capillary leak syndrome (I78.8), thrombocytopenia (D69.59), leukocytosis (D72.829), cutaneous vasculitis (D69.0), or bones and muscle ache (M85.80, G72.0).

\section{TABLE 2 Baseline Demographic Characteristics}

\begin{tabular}{|c|c|c|c|c|c|}
\hline \multirow[b]{2}{*}{ Age, mean $( \pm S D)$ years } & \multicolumn{2}{|c|}{$\begin{array}{l}\text { Filgrastim } \\
\quad(n=88)\end{array}$} & \multicolumn{2}{|c|}{$\begin{array}{l}\text { Filgrastim-snd } z \\
\quad(\mathrm{n}=101)\end{array}$} & \multirow{2}{*}{$\frac{P \text { Value }}{-}$} \\
\hline & 71.3 & $(12.1)$ & 68.4 & $(11.0)$ & \\
\hline \multicolumn{6}{|l|}{ Age, n (\%) } \\
\hline $19-59$ years & 12 & (13.6) & 14 & (13.9) & \multirow{4}{*}{$<0.001$} \\
\hline $60-69$ years & 16 & (18.2) & 34 & (33.7) & \\
\hline 70-79 years & 36 & $(40.9)$ & 43 & $(42.6)$ & \\
\hline $80-89$ years & 24 & $(27.3)$ & 10 & (9.9) & \\
\hline \multicolumn{6}{|l|}{ Sex, n (\%) } \\
\hline Female & 49 & $(55.7)$ & 65 & $(64.4)$ & \multirow{2}{*}{0.224} \\
\hline Male & 39 & $(44.3)$ & 36 & $(35.6)$ & \\
\hline
\end{tabular}

$S D=$ standard deviation .

\section{Data Analyses}

Continuous variables were summarized using means and standard deviations, while categorical variables were summarized using percentages. Differences between patients taking filgrastim and patients taking filgrastim-sndz on age (categorical) and sex were evaluated using chi-square tests The a priori alpha level for relevant analyses was set at 0.05, and analyses were 2-tailed. All analyses were performed using SAS Enterprise Guide, version 7.1 (SAS Institute, Cary, NC).

The incidence differences of neutropenia episodes requiring hospitalization and serious adverse events were derived by subtracting the incidence in the filgrastim-sndz cohort from the incidence in the filgrastim cohort. The 90\% confidence intervals (CIs) were calculated for each incidence difference. ${ }^{8}$ For analysis of noninferiority, an incidence difference less than $1 \%$ with $90 \%$ CI that crossed zero was considered noninferior. In addition, differences in incidence rates were evaluated using chi-square tests to provide an additional check even though sample sizes were not sufficient to establish noninferiority using a statistical test of differences such as chi-square. The chosen criteria for establishing noninferiority was a less than $1 \%$ difference in the incidence combined with evaluation of the $90 \%$ CI. Selection of less than $1 \%$ incidence difference and 90\% CI was based, in part, on published comparative effectiveness studies. The filgrastim versus filgrastim-sndz study by Hegg et al. (2016) set the margin of noninferiority as less than $15 \%$ for incidence of grade 4 neutropenia, as assessed via direct evaluation of patients, and did not require hospitalization. ${ }^{8}$ Since the current study used a more conservative operational definition of neutropenia that required hospitalization and was determined based on administrative claims, a stricter margin of noninferiority was appropriate.

\section{Results}

\section{Study Population}

A total of 189 patients had a medical or pharmacy claim for filgrastim $(n=88)$ or filgrastim-sndz $(n=101)$ during the 


\begin{tabular}{|c|c|c|c|c|}
\hline \multicolumn{5}{|c|}{ Filgrastim vs. Filgrastim-sndz } \\
\hline Measure & Filgrastim (\%) & Filgrastim-sndz (\%) & Incidence Difference (\%) & $P$ Value \\
\hline \multicolumn{5}{|c|}{ Febrile neutropenia requiring hospitalization, IR $(90 \% \mathrm{CI})$} \\
\hline Infection and/or neutropenia & $3.4 \quad(0.9-8.6)$ & $(1.4-8.8)$ & $-0.6 \quad(-5.1-4.0)$ & 0.84 \\
\hline Infection and neutropenia & $(0.1-5.3)$ & $(0.4-6.1)$ & $-0.8^{\mathrm{a}}(-3.8-2.1)$ & 0.64 \\
\hline \multicolumn{5}{|l|}{ Safety outcomes, IR $(90 \% \mathrm{CI})$} \\
\hline Adverse drug event & $(0.9-8.6)$ & $(2.6-11.4)$ & $-2.5 \quad(-7.5-2.5)$ & 0.42 \\
\hline
\end{tabular}

identification period (Figure 1). The filgrastim and filgrastimsndz groups were similar in terms of sex, but the mean age was higher in the filgrastim cohort $(P<0.001$; Table 2$)$.

\section{Effectiveness and Safety of Filgrastim and Filgrastim-sndz}

When comparing filgrastim and filgrastim-sndz, noninferiority was established based on the broad and narrow definitions for febrile neutropenia requiring hospitalization, with $-0.6 \%(90 \%$ $\mathrm{CI}=-5.1 \%-4.0 \%, P=0.84)$ and $-0.8 \%(90 \% \mathrm{CI}=-3.8 \%-2.1 \%$, $P=0.64$ ) incidence differences, respectively (Table 3 ). Filgrastim-sndz had a nonsignificant, but slightly higher, incidence of serious adverse events; however, the difference was too large to establish noninferiority $(2.5 \%, 90 \% \mathrm{CI}=-7.5 \%-2.5 \%$, $P=0.42$; Table 3).

\section{Discussion}

The findings in this study are some of the earliest published results examining clinical equivalency for biosimilars in the real-world setting. The results show an early picture of noninferiority between filgrastim and filgrastim-sndz, using a broad and a narrow definition for febrile neutropenia requiring hospitalization. This result will be of some comfort to the clinicians and systems that advocated for the early adoption of filgrastimsndz. However, findings for adverse drug events did not show clear equivalence nor were there significant differences in the incidence of serious adverse events between filgrastim and filgrastim-sndz.

An incidence difference of less than $1 \%$ was selected as the margin of noninferiority for this study, but determining the boundaries for noninferiority analysis is not well defined and is especially nebulous when conducting real-world and observational studies. The guidelines proposed by the International Conference on Harmonization suggest that trial designers should select a margin of noninferiority that is equal to or smaller than the smallest effect size that might be expected in a trial comparing one of the active drugs with a placebo. ${ }^{10} \mathrm{~A}$ systematic review of placebo-controlled filgrastim trials among patients with a variety of cancers reports neutropenia incidence differences ranging from $8.2 \%$ to $36.9 \% .^{11}$ The smallest effects observed were $8.2 \%$ in a study of patients with non-Hodgkins lymphoma and $9.9 \%$ incidence difference in a study of patients with germ cell cancer. ${ }^{12,13}$ Because our study required hospitalization for febrile neutropenia, a margin of noninferiority of $1 \%$ was appropriate even if the margin was somewhat conservative.

\section{Limitations}

Limitations common to studies using administrative claims data apply to this study, which used data from the Humana Research Database only, so results may not be generalizable to all patient populations using G-CSF for prophylaxis of neutropenia. The average age for the study sample was within expectations given that Humana serves many Medicare-eligible patients and the increasing probability of invasive cancer with increasing age..$^{14}$

Using administrative claims data limited observations of febrile neutropenia and adverse drug events in this study, since diagnosis coding based on ICD-10-CM, as applied to administrative claims, is not expected to identify all cases of neutropenia or all cases of serious adverse events. This study used 2 operational definitions for neutropenia that were limited to neutropenic events requiring hospitalization so missed lower severity neutropenia events. In addition, the operational definition for serious adverse events almost certainly missed a number of actual adverse drug events, possibly even some severe adverse drug events, since only those events that required a medical service claim could be observed. Furthermore, ICD-10-CM codes do not cover all the adverse drug events (e.g., certain localized pain or feeling of fullness) that may be associated with G-CSF products.

Overall, the analyses of study outcomes were limited by the relatively small number of patients using filgrastim or filgrastim-sndz and meeting the study criteria. The primary outcome evaluated for this study was somewhat rare, with febrile neutropenia requiring hospitalization occurring in less than $4 \%$ of the sample based on the broad definition and less than $2 \%$ based on the narrow definition. The broad and narrow definitions used for febrile neutropenia were fairly specific, and group sizes of 88 and 101 patients taking filgrastim and filgrastim-sndz, respectively, should be sufficient for detecting the incidence of events, although larger group sizes would be preferred. 
The secondary outcome, incidence of a serious adverse event, was more limited by small group sizes because specific, serious adverse events were expected to be so rare that incidence could not adequately be detected within this study. A composite measure to capture any type of serious adverse event was used for the study in an attempt to mitigate the limitations due to rarity of the outcome and small group sizes. With use of a composite measure, serious adverse events were observed in greater than $3 \%$ of the sample.

This study included patients receiving G-CSF regardless of primary cancer site or chemotherapy regimen, so the actual risk of neutropenia and/or adverse drug events could have varied among the study cohort. Interpretation of study findings should consider these limitations. Future studies should account for differences in neutropenia risk among cohorts that may be attributed to cancer site or chemotherapy regimen, if such differences are observed.

\section{Conclusions}

This real-world study suggests that filgrastim and filgrastimsndz were noninferior for prevention of febrile neutropenia events that require hospitalization, but noninferiority based on incidence differences for serious adverse events was not established. These conclusions are limited by the relatively small sample size for the study. The conclusions regarding noninferiority are also specific to the margin of noninferiority selected for the analysis and could be subject to change if an alternative margin were deemed more appropriate for the outcome of febrile neutropenia requiring hospitalization or for the outcome of a serious adverse drug event.

\section{Authors}

ANDREA G. DOUGLAS, PharmD; KENNETH KENNEDY, PharmD, MS, BCOP; and S. LANE SLABAUGH, PharmD, MBA, Humana Pharmacy Solutions, Humana, Louisville, Kentucky. PHIL SCHWAB, PhD; DANIEL LANE, PharmD, PhD; and ANDY BOWE, MPH, Comprehensive Health Insights, Humana, Louisville, Kentucky.

AUTHOR CORRESPONDENCE: Phil Schwab, PhD, Humana, 515 W. Market, Louisville, KY 40202. Tel.: 502.476.5610;

E-mail: pschwab@humana.com.
Study concept and design were contributed by Douglas, Kennedy, Schwab, and Lane, along with Slabaugh and Bowe. Bowe took the lead in data collection, assisted by Schwab, and data interpretation was performed by Schwab, along with the other authors. The manuscript was written by Schwab, Lane, and Douglas and revised by Kennedy, Slabaugh, and Bowe, along with Schwab, Lane, and Douglas.

\section{ACKNOWLEDGMENTS}

Editorial assistance was provided by Charron Long, PharmD, an employee of Humana.

\section{REFERENCES}

1. Biologic Price Competition and Innovation Act. Title VII, Subtitle A of H.R. 3590. 111th Congress (2009-2010). Enacted. Available at: https:// www.fda.gov/downloads/drugs/guidancecomplianceregulatoryinformation/ ucm216146.pdf. Accessed October 31, 2017.

2. U.S. Food and Drug Administration. FDA approves first biosimilar product Zarxio. FDA news release. March 6, 2015. Available at: https://www.fda. gov/Drugs/InformationOnDrugs/ApprovedDrugs/ucm436648.htm. Accessed October 31, 2017

3. Zarxio (filgrastim-sndz) injection, for subcutaneous or intravenous use. Sandoz. Revised February 2017. Available at: http://www.zarxio.com/ globalassets/zarxio2/resources/materials/S-Zarxio-Prescribing-InformationFeb-2017.pdf. Accessed November 8, 2017.

4. Neupogen (filgrastim) injection, for subcutaneous or intravenous use. Amgen. Revised July 2015. Available at: https://www.accessdata.fda.gov/ drugsatfda_docs/label/2015/103353s5186lbl.pdf. Accessed October 31, 2017.

5. Granix (tbo-filgrastim) injection, for subcutaneous use. Sicor Biotech UAB. Revised December 2014. Available at: https://www.accessdata.fda.gov/ drugsatfda_docs/label/2014/125294s035lbl.pdf. Accessed October 31, 2017.

6. Neulasta (pegfilgrastim) injection, for subcutaneous use. Amgen. Revised November 2015. Available at: https://www.accessdata.fda.gov/drugsatfda_ docs/label/2015/125031s180lbl.pdf. Accessed October 31, 2017.

7. Sandoz. FDA oncologic drugs advisory committee meeting document: Zarxio (filgrastim-sndz). FDA Advisory Committee Briefing. Table 20Summary of ZARXIO clinical efficacy studies. January 7, 2015. Page 69. Available at: https://www.fda.gov/downloads/AdvisoryCommittees/ CommitteesMeetingMaterials/Drugs/OncologicDrugsAdvisoryCommittee/ UCM428782.pdf. Accessed October 31, 2017.

8. Hegg R, Mattar A, Nunes de Matos-Neto J, et al. A phase III, randomized, non-inferiority study comparing the efficacy and safety of biosimilar filgrastim versus originator filgrastim for chemotherapy-induced neutropenia in breast cancer patients. Clinics (Sao Paulo). 2016;71(10):586-92 Available at: http://www.scielo.br/scielo.php?script=sci_arttext\&pid=S180759322016001000586\&lng=en\&nrm=iso\&tlng=en. Accessed October 31, 2017.

9. Naiem A, Henk HJ, Becker L, et al. Pegfilgrastim prophylaxis is associated with a lower risk of hospitalization of cancer patients than filgrastim prophylaxis: a retrospective United States claims analysis of granulocyte colonystimulating factors (G-CSF). BMC Cancer. 2013:13:11. Available at: https:// bmccancer.biomedcentral.com/articles/10.1186/1471-2407-13-11. Accessed October 31, 2017.

10. International Conference on Harmonisation of Technical Requirements for Registration of Pharmaceuticals for Human Use. E10 Choice of control group and related issues in clinical trials. July 20, 2000. Available at: http:// www.ich.org/products/guidelines/efficacy/efficacy-single/article/choice-ofcontrol-group-and-related-issues-in-clinical-trials.html. Accessed October 31, 2017

11. Cooper KL, Madan J, Whyte S, et al. Granulocyte colony-stimulating factors for febrile neutropenia prophylaxis following chemotherapy: systematic review and meta-analysis. BMC Cancer. 2011;11:404.
This study received no outside funding. Douglas, Kennedy, and Slabaugh were employees of Humana Pharmacy Solutions at the time the study was conducted. Bowe, Schwab, and Lane were employees of Comprehensive Health Insights, a wholly owned subsidiary of Humana, at the time the study was conducted. 
12. Doorduijn JK, van der HB, van Imhoff GW, et al. CHOP compared with CHOP plus granulocyte colony stimulating factor in elderly patients with aggressive non-Hodgkin's lymphoma. J Clin Oncol. 2003;21(16):3041-50.

13. Fossa SD, Kaye SB, Mead GM, et al. Filgrastim during combination chemotherapy of patients with poor-prognosis metastatic germ cell malignancy. European Organization for Research and Treatment of Cancer,

Genito-Urinary Group, and the Medical Research Council Testicular Cancer Working Party, Cambridge, United Kingdom. J Clin Oncol. 1998;16(2):716-24.
14. American Cancer Society. Cancer facts \& figures 2016. Available at: https://www.cancer.org/content/dam/cancer-org/research/cancer-factsand-statistics/annual-cancer-facts-and-figures/2016/cancer-facts-and-figures-2016.pdf. Accessed October 31, 2017. 